\title{
Evaluation of Estimation Methods for Shear Fatigue Properties and Correlations with Uniaxial Fatigue Properties for Steels and Titanium Alloys
}

\author{
Shahriar Sharifimehr ${ }^{1, *}$, Ali Fatemi $^{2}$ \\ ${ }^{1}$ Mechanical, Industrial and Manufacturing Engineering, University of Toledo, Toledo, Ohio, USA \\ ${ }^{2}$ Mechanical Engineering, University of Memphis, Memphis, Tennessee, USA
}

\begin{abstract}
The goal of this study was to evaluate the accuracy of different methods in correlating uniaxial fatigue properties to shear fatigue properties, as well as finding a reliable estimation method which is able to predict the shear fatigue behavior of steels and titanium alloys from their monotonic properties. In order to do so, axial monotonic as well as axial and torsion fatigue tests were performed on two types of steel and a Ti-6Al-4V alloy. The results of these tests along with test results of 23 types of carbon steel, Inconel 718, and three types of titanium alloys commonly used in the industry were analyzed. It was found that von Mises and maximum principal strain criteria were able to effectively correlate uniaxial fatigue properties to shear fatigue properties for ductile and brittle behaving materials, respectively. Also, it was observed that for steels and Inconel 718 obtaining shear fatigue properties from uniaxial fatigue properties which are in turn calculated from Roessle-Fatemi estimation method resulted in reasonable estimations when compared to experimentally obtained uniaxial fatigue properties. Furthermore, a modification was made to the Roessle-Fatemi hardness method in order to adjust it to fatigue behavior of titanium alloys. The modified method, which was derived from uniaxial fatigue properties of titanium alloys with Brinell hardness between 240 and 353 proved to be accurate in predicting the shear fatigue behaviors.
\end{abstract}

\section{Introduction}

Mechanical properties, both monotonic and fatigue, are key information in efficient design of components. Monotonic properties are usually easy to obtain and available for many metallic materials. However, characterizing the fatigue behavior of materials requires conducting time consuming fatigue tests. Therefore, fatigue properties of metallic materials are not as commonly available as their monotonic properties. This is in spite of the fact that fatigue is a major consideration in design and up to 90 percent of all mechanical failures are fatigue failures [1].

In many cases engineers tend to estimate the fatigue properties of materials throughout the design process. The estimation methods often correlate the uniaxial monotonic properties of metallic materials, and especially steels, with their uniaxial strain-life fatigue properties. Methods such as four-point correlation proposed by Manson [2], modified four-point correlation proposed by Ong [3], universal slopes proposed by Manson [2], modified universal slopes proposed by Muralidharan and Manson [4], and uniform material law proposed by Bäumel and Seeger [5] have shown to result in close predictions of fatigue behavior for many steels. While the aforementioned studies used monotonic properties in estimation of fatigue properties, Roessle and Fatemi [6] proposed and evaluated a correlation method which only used elastic modulus and Brinell hardness of steels. The Roessle-Fatemi method was shown to result in close predictions for uniaxial fatigue tests on 69 commonly used steels. This method has been widely used by many researchers and many studies such as [7-10] have shown good prediction results using this method.

Uniaxial fatigue properties estimated from the aforementioned methods are able to model the fatigue behavior of components which are subjected to uniaxial cyclic loadings. However, in many cases the load histories subjected to components are either shear loads or a combination of normal and shear loads resulting in a multiaxial stress state. Even under uniaxial loading the stress state may still be multiaxial due to many factors such as complex geometry of components and presence of residual stresses. Shear fatigue properties are used to model the fatigue behavior of materials which are subjected to cyclic shear loadings. Equivalent stress and strain methods such as von Mises are able to correlate the fatigue behavior of many metallic materials under different proportional load paths with their uniaxial fatigue behavior. However, the equivalent stress and strain methods often cannot model the fatigue behavior under non-proportional load paths.

In recent years critical plane approaches have become popular due to their ability to establish a correlation between the fatigue behavior of metallic materials under

Corresponding author: shahriar.sharifimehr@,rockets.utoledo.edu 
complex non-proportional load paths and those under uniaxial and proportional load paths. The most commonly used critical plane approaches such as Fatemi-Socie model [11] use shear fatigue properties as the base of their correlations. Therefore, in categorizing the fatigue behavior of materials shear fatigue properties are as important and useful as uniaxial fatigue properties. However, due to complexities of torsional fatigue tests shear fatigue properties are available for a small number of materials, as compared to uniaxial fatigue properties. This highlights the importance of reliable methods which can reasonably estimate the shear fatigue properties of materials based on their uniaxial mechanical properties.

There are very small number of studies in the open literature on the estimation of shear fatigue properties of a small number of metallic materials. For instance, Shamsaei and Fatemi [12] used different correlation methods to estimate the shear fatigue properties of SAE 1050 case-hardened specimens from their uniaxial fatigue behavior. Since the specimens were casehardened and due to the fact the stress gradient in torsion fatigue tests result in higher shear stress on the surface, they analyzed their test results based on the fatigue properties of the hardened case. The criteria used in this study were Tresca (maximum shear stress), von Mises, and maximum principal strain. It was concluded that correlations based on the maximum principal strain criterion resulted in a close prediction of the shear strainfatigue life behavior of the specimens while von Mises and Tresca criteria significantly underestimated the fatigue life.

Leese and Morrow [13] also used maximum shear stress and von Mises criteria in order to estimate shear cyclic and fatigue properties of 1045 steel from their axial counterparts. They observed that while maximum shear stress was able to estimate shear cyclic properties with better accuracy compared to von Mises, both equivalent stress criteria resulted in a reasonably close estimation of shear fatigue behavior of the material.

The most notable study on the estimation of shear fatigue properties of steels was conducted by Kim et al. [7]. In their study uniaxial and torsional monotonic and fatigue tests were conducted on eight ductile steels and several methods for estimating uniaxial fatigue properties were evaluated. It was found that modified universal slopes and Roessle-Fatemi hardness method resulted in good life predictions for uniaxial tests. Furthermore, based on von Mises equivalent stress and strain uniaxial fatigue properties estimated from the aforementioned methods were converted to shear fatigue properties. Torsional fatigue life predictions from these estimated properties were reported to be reasonably close to the experimental lives with $85 \%$ of life predictions falling within a factor of 3 of the experimental fatigue life data.

The goal of this study was to evaluate the performance of different methods in predicting the shear fatigue behavior of several classes of metallic materials from estimated uniaxial fatigue properties. In order to achieve this goal results of monotonic and fatigue tests on several metallic materials found in the literature were analyzed. In addition, uniaxial and torsional monotonic and fatigue tests were conducted on two types of steel alloy and one wrought titanium alloy, the results of which were added to the data pool. Two general methods were used in the estimation of shear fatigue properties. In the first method the experimentally obtained uniaxial fatigue properties were converted to shear fatigue properties. In the second method the uniaxial fatigue properties were estimated from the Roessle-Fatemi hardness-based method and the estimated uniaxial fatigue properties were then converted to shear fatigue properties. In both methods, depending on the level of hardness of the materials, different criteria were used in correlating uniaxial fatigue properties to shear fatigue properties. In the following sections the experimental program, the materials used in the data pool, the estimation methods, and the performed analysis are presented in detail and the obtained results are discussed.

\section{Experimental Program and Results}

Two types of steel alloy as well as wrought titanium alloy Ti-6Al-4V were subjected to monotonic and cyclic axial and torsion tests. The two types of steel tested in this study are 44MnSiVS6 and SUPM125 which are used in the crankshafts and coil springs of vehicles in the auto industry, respectively. The 44MnSiVS6 steel specimens were hot forged and controlled cooled, while the SUPM125 steel specimens were hot formed and quenched and tempered. The wrought titanium specimens were made from machining pre-annealed solid bars of grade $5 \mathrm{Ti}-6 \mathrm{Al}-4 \mathrm{~V}$ with nominal diameter of $28.6 \mathrm{~mm}$. All of the steel and titanium specimens were thin-wall tubular with a wall thickness of $1.25 \mathrm{~mm}$ which were designed according to ASTM Standard E2207 [14].

An Instron closed-loop servo-controlled hydraulic axial-torsion load frame was used to conduct the monotonic and fatigue tests. The alignment of the load frame was verified to produce no more than $5 \%$ bending which is recommended by ASTM Standard E1012-12 [15]. All of the fatigue tests were performed in fully reversed mode $(R=-1)$ using sinusoidal waveform. The obtained mechanical properties of these materials as well as their Brinell hardness are shown in Table 1. In this table $E$ and $G$ are elastic moduli under axial and shear loadings, respectively. Furthermore, $S_{u}$ is the ultimate tensile strength, $\mathrm{HB}$ is the Brinell hardness, $\sigma_{f}^{\prime}$ is fatigue strength coefficient, $\varepsilon_{f}^{\prime}$ is fatigue ductility coefficient, $b$ is fatigue strength exponent, $c$ is fatigue ductility exponent, $\tau_{f}^{\prime}$ is shear fatigue strength coefficient, $\gamma_{f}^{\prime}$ is shear fatigue ductility coefficient, $b_{0}$ is shear fatigue strength exponent, and $c_{0}$ is shear fatigue ductility exponent.

\section{Data Pool from Literature}

In addition to the tested materials, shear fatigue data for 23 carbon steels were found in the literature. According to the classification of American Iron and Steel Institute (AISI) among the steels in the data pool 8 were categorized as low-carbon steels with less than 
$0.3 \%$ carbon content, 13 were categorized as mediumcarbon steels with $0.3-0.6 \%$ carbon content, and 4 were categorized as high-carbon steels with $0.6-1.0 \%$ carbon content. $605 \mathrm{H} 32$ steel which is one of the medium carbon steels used in the data pool had been tested at elevated temperatures of $300{ }^{\circ} \mathrm{C}$ and $600{ }^{\circ} \mathrm{C}$ [16]. The test results in the two conditions were analyzed separately. In addition, the 4 types of high-carbon steel used in the data pool were variants of 52100 steel and, thus, shared the same chemical composition [17]. However, since they have different monotonic and fatigue properties they were also analyzed separately.

The ultimate tensile strength of the steels ranged from as low as $316 \mathrm{MPa}$ to as high as $2636 \mathrm{MPa}$ which covers most of the grades of carbon steel used in the industry. Furthermore, test data of commercial pure titanium, titanium alloy BT9, and titanium alloy TC4 were added to the data pool. The data pool also consisted of test data for Inconel 718, an austenitic nickelchromium-based superalloy commonly used in gas turbine blades. All of the fatigue tests were performed on tubular specimens with machined and smooth surface. The fatigue crack orientation of the materials in each study was also considered. It was found that fatigue cracks in steels with ultimate tensile strength of 1100 MPa or less $(\mathrm{HB} \leq 327)$ initiated on the maximum shear planes, while fatigue cracks in most of the steels with ultimate tensile strength of $1696 \mathrm{MPa}$ or higher (HB $\geq$ 443 ) initiated on the plane of maximum principal stress. Spring steel with ultimate tensile strength of $2208 \mathrm{MPa}$ $(\mathrm{HB}=615)$ was the only exception with cracks initiating on the plane of maximum shear strain.

It should be noted that in the process of selecting materials and test data for the data pool the case hardened and case carburized materials were avoided. The reason is that specimens which go through the process of case hardening and case carburizing have a hard case and a softer core. The inhomogeneity of hardness in these specimens in addition to the stress gradient caused by torsional loading result in inconsistencies in correlations between uniaxial and shear fatigue properties. The details of the experiments on the materials used in the data pool can be found in [7, 13, 16-29] and monotonic and fatigue properties are presented in Table

Table 1. Obtained mechanical properties and Brinell hardness of the materials used in the data pool.

\begin{tabular}{|c|c|c|c|c|c|c|c|}
\hline Material & $E / G(\mathbf{G P a})$ & $\begin{array}{c}S_{u} \\
\text { (MPa) }\end{array}$ & HB & $\begin{array}{c}\sigma_{f}^{\prime} / \tau_{f}^{\prime} \\
(\mathbf{M P a})\end{array}$ & $\varepsilon_{f}^{\prime} / \gamma_{f}^{\prime}$ & $b / b_{0}$ & $c / c_{0}$ \\
\hline \multicolumn{8}{|c|}{ Steel } \\
\hline Mild Steel [18] & $210.0 / 74.8$ & 316 & & $1185 / 497$ & $3.341 / 0.530$ & $-0.167 /-0.142$ & $-0.748 /-0.478$ \\
\hline $1045[13]$ & \begin{tabular}{|l|}
$202.4 / 79.1$ \\
\end{tabular} & 484 & 153 & $948 / 505$ & $0.260 / 0.413$ & $-0.092 /-0.097$ & $-0.445 /-0.445$ \\
\hline S25C [17] & $209 / 80$ & 508 & 153 & $821 / 426$ & $0.216 / 0.249$ & $-0.096 /-0.074$ & $-0.458 /-0.376$ \\
\hline 1045 HR [19] & $206.0 / 82.3$ & 565 & - & $1035 / 444$ & $0.334 / 0.326$ & $-0.108 /-0.078$ & $-0.491 /-0.416$ \\
\hline St52-3N [20] & $206 / 78$ & 639 & - & $564 / 333$ & $0.156 / 0.081$ & $-0.058 /-0.043$ & $-0.466 /-0.323$ \\
\hline S460N [21] & $208.5 / 80.2$ & 643 & - & $1002 / 477$ & $0.147 / 0.316$ & $-0.097 /-0.075$ & $-0.487 /-0.469$ \\
\hline AISI 304 SS [22] & $183.0 / 82.8$ & 650 & - & $1151 / 781$ & $0.171 / 0.380$ & $-0.132 /-0.131$ & $-0.400 /-0.369$ \\
\hline Ni-Cr-Mo-V [23] & $200.0 / 80.7$ & 724 & - & $680 / 394$ & $1.14 / 1.12$ & $-0.043 /-0.039$ & $-0.690 /-0.570$ \\
\hline 304 SS [24] & $171 / 66$ & 754 & - & $647 / 1009$ & $0.105 / 0.231$ & $-0.056 /-0.126$ & $-0.391 /-0.386$ \\
\hline S45C [25] & $186.0 / 72.7$ & 770 & - & $923 / 685$ & $0.359 / 0.198$ & $-0.099 /-0.120$ & $-0.519 /-0.360$ \\
\hline S45C [7] & $206 / 79$ & 798 & 234 & $1400 / 630$ & $0.449 / 1.22$ & $-0.107 /-0.080$ & $-0.564 /-0.564$ \\
\hline SF60 [7] & $208 / 79$ & 820 & 167 & $978 / 504$ & $0.187 / 0.286$ & $-0.082 /-0.067$ & $-0.439 /-0.417$ \\
\hline SFNCM85S [7] & $201 / 80$ & 825 & 241 & $1040 / 533$ & $0.316 / 0.251$ & $-0.092 /-0.071$ & $-0.522 /-0.406$ \\
\hline SCM435 [7] & $210 / 81$ & 951 & 300 & $1100 / 512$ & $0.996 / 0.360$ & $-0.067 /-0.045$ & $-0.708 /-0.519$ \\
\hline 44MnSiVS6 (Crankshaft Steel) & $209.2 / 80.3$ & 960 & 280 & $1188 / 611$ & $2.01 / 0.486$ & $-0.070 /-0.053$ & $-0.737 /-0.539$ \\
\hline $605 \mathrm{H} 32$ at $600{ }^{\circ} \mathrm{C}[16]$ & $208 * / 80$ & 972 & 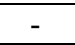 & -1455 & $-/ 1.02$ & $-/-0.030$ & $-/-0.557$ \\
\hline SCM440 [7] & $204 / 80$ & 1000 & 319 & $1400 / 662$ & $0.675 / 1.31$ & $-0.088 /-0.071$ & $-0.650 /-0.656$ \\
\hline 30CrNiMo8HH [26] & $208 * / 80$ & 1025 & 314 & $973 / 1002$ & $1.74 / 0.148$ & $-0.040 /-0.055$ & $-0.732 /-0.430$ \\
\hline SNCM439 [7] & $208 / 80$ & 1050 & 323 & $1380 / 969$ & $1.89 / 3.68$ & $-0.072 /-0.086$ & $-0.801 /-0.765$ \\
\hline SNCM630 [7] & $196 / 77$ & 1100 & 327 & $1270 / 858$ & $1.54 / 1.51$ & $-0.073 /-0.061$ & $-0.823 /-0.706$ \\
\hline $605 \mathrm{H} 32$ at $300^{\circ} \mathrm{C}[16]$ & $202.8 * / 78$ & 1696 & - & $-/ 1277$ & $-/ 0.382$ & $-/-0.078$ & $-/-0.0561$ \\
\hline SUPM125 (Spring Steel) & $206.8 / 79.5^{*}$ & 2208 & 615 & $6332 / 1571$ & $-/ 0.100$ & $-0.185 /-0.065$ & $-/-0.487$ \\
\hline 52100 Type E [17] & $210 * / 80^{*}$ & 2391 & - & -12757 & $-1-$ & $-/-0.107$ & $-1-$ \\
\hline 52100 Type $\mathrm{C}[17]$ & $0 * / 80 *$ & 2527 & - & $-/ 2716$ & $-1-$ & $-/-0.104$ & $-1-$ \\
\hline 52100 Type B [17] & $210^{*} / 80^{*}$ & 2588 & - & $-/ 2776$ & $-1-$ & $-/-0.101$ & $-1-$ \\
\hline 52100 Type A [17] & $210 * / 80^{*}$ & 2636 & - & $-/ 2829$ & $-1-$ & $-/-0.102$ & $-1-$ \\
\hline \multicolumn{8}{|c|}{ Titanium } \\
\hline Pure Titanium [27] & $2 / 40$ & 558 & 240 & $647 / 485$ & $0.548 / 0.417$ & $-0.033 /-0.069$ & $-0.646 /-0.523$ \\
\hline TC4 [28] & $\begin{array}{ll}108.4 / 43.2 \\
\end{array}$ & 1044 & 353 & $1146 / 584$ & $0.614 / 2.39$ & $-0.052 /-0.043$ & $-0.690 /-0.790$ \\
\hline Wrought T & & 1045 & 353 & $987 / 647$ & $0.569 / 0.352$ & $-0.034 /-0.044$ & $-0.636 /-0.502$ \\
\hline BT9 [27] & $118 / 43$ & 1080 & 349 & $1180 / 881$ & $0.278 / 0.180$ & $-0.025 /-0.082$ & $-0.665 /-0.470$ \\
\hline \multicolumn{8}{|c|}{ Inconel } \\
\hline Inconel 718 [29] & $208.5 / 77.8$ & 1420 & 371 & $1897 / 1672$ & $5.815 / 9.500$ & $-0.07 /-0.121$ & $-0.906 /-0.852$ \\
\hline
\end{tabular}


The materials in bold are tested in this study.

* The Poisson's ratios and the elastic moduli were assumed by the authors.

\section{Estimation Methods and Analysis}

In the presence of uniaxial fatigue properties the shear fatigue properties are usually estimated from these properties using different criteria. The suitable criterion should be chosen based on the behavior of the material. Criteria such as von Mises equivalent stress and strain are used for ductile behaving materials, while criteria such as maximum principal strain are used for brittle behaving materials. The estimation equations based on von Mises and maximum principal strain are expressed as:

$$
\begin{gathered}
\tau_{f}^{\prime}=\frac{\sigma_{f}^{\prime}}{\sqrt{3}}, \gamma_{f}^{\prime}=\sqrt{3} \varepsilon_{f}^{\prime}, b_{0}=b, c_{0}=c \\
\tau_{f}^{\prime}=\frac{\sigma_{f}^{\prime}}{1+v}, \gamma_{f}^{\prime}=2 \varepsilon_{f}^{\prime}, b_{0}=b, c_{0}=c
\end{gathered}
$$

respectively, where $v$ is the Poisson's ratio. However, when the uniaxial fatigue properties are not available for a material, correlation techniques should be employed to estimate these properties from monotonic tension properties. Roessle-Fatemi equation is one of the most commonly used estimation methods which estimates the uniaxial fatigue properties of steel alloys from their elastic modulus and Brinell hardness (HB):

$$
\begin{gathered}
\sigma_{f}^{\prime}=4.25(\mathrm{HB})+225 \\
\varepsilon_{f}^{\prime}=\frac{0.32(\mathrm{HB})^{2}-478(\mathrm{HB})+191000}{E}
\end{gathered}
$$

In this method, fatigue strength and ductility exponents ( $b$ and $c$ ) are the same as the exponents used in the Modified Universal Slopes Method and are equal to 0.09 and -0.56 , respectively. For materials the hardness of which is not available Brinell hardness can be estimated from the following equation [6]:

$$
S_{u}=0.0012(\mathrm{HB})^{2}+3.3(\mathrm{HB})
$$

Depending on the fatigue behavior of the material one of the criteria expressed in Eq. 1 or 2 is used to obtain the shear fatigue properties from the estimated uniaxial fatigue properties.

\subsection{Prediction Results for Steels and Inconel 718}

Using von Mises criterion for ductile behaving materials and maximum principal strain criterion for brittle behaving materials shear fatigue properties were calculated from both experimental uniaxial properties and uniaxial properties estimated from Roessle-Fatemi hardness method. Then, results of torsional fatigue tests were predicted using the estimated shear fatigue properties and presented in log-log plots of predicted vs. experimental total shear strain amplitudes, as well as predicted vs. experimental fatigue lives. These plots are shown in Figures 1 and 2 for predictions from experimental uniaxial fatigue properties and uniaxial properties estimated from Roessle-Fatemi hardness method, respectively. It should be noted that since experimentally obtained uniaxial fatigue properties of $605 \mathrm{H} 32$ and 52100 steels were not available they are not included in Figure 1.

By comparing Figures 1(a) and 2(a) it can be observed that predictions from Roessle-Fatemi method were closer to the experimental values than those from experimentally obtained uniaxial properties as the percentage of data within each scatter band for Roessle-Fatemi method is higher. For example, $74 \%$ of data fell within the strain scatter band of 1.2 for Roessle-Fatemi method, while this percentage for predictions from experimentally obtained uniaxial properties was only $38 \%$. Furthermore, the percentage of data falling within a life factor of 3 for uniaxial fatigue properties method and Roessle-Fatemi method were $70 \%$ and $83 \%$, respectively. Moreover, both methods showed reasonable predictions for Inconel 718 as well.

\subsection{Prediction Results for Titanium}

Figure 3 shows the prediction results of shear fatigue tests on titanium alloys based on experimentally obtained uniaxial fatigue properties. All of the titanium alloys were classified as ductile behaving materials and only von Mises criterion was used in the correlation of properties. Good results were observed in predictions of shear strain amplitudes shown in Figure 3(a) in both $\mathrm{HCF}$ and LCF regions. However, predictions of fatigue lives shown in Figure 3(b) show scatter in HCF region. This is due to the very shallow slopes of shear strain amplitude-fatigue life curves of titanium alloys in the elastic region.

Since the Roessle-Fatemi prediction method is developed for steels it cannot be used for titanium alloys unless it is modified based on the fatigue behavior of these alloys. However, since only a few number of titanium alloys were found in the literature and used in the data pool, the applicability of the proposed modifications to other types of titanium alloys which are not present in the data pool needs to be evaluated. In this study the estimation of fatigue ductility coefficient for steels, shown in Eq. 4, is modified for titanium alloys.

In order to do so, a procedure similar to the procedure described by Roessle and Fatemi [6] was followed for the titanium materials in the data pool. The following linear relationship was derived for the titanium alloys in the data pool:

$$
\varepsilon_{f}^{\prime}=\frac{-44(\mathrm{HB})+43000}{E}
$$

Fatigue strength and fatigue ductility coefficients calculated from Eqs. 3 and 6 along with fatigue strength and ductility exponents of -0.09 and -0.56 , respectively, were used as the Roessle-Fatemi 
estimation method modified for titanium alloys. The final equation is shown below.

$$
\frac{4.25(\mathrm{HB})+225}{E}\left(2 N_{f}\right)^{-0.09}+\frac{-44(\mathrm{HB})+43000}{E}\left(2 N_{f}\right)^{-0.56}(7)
$$

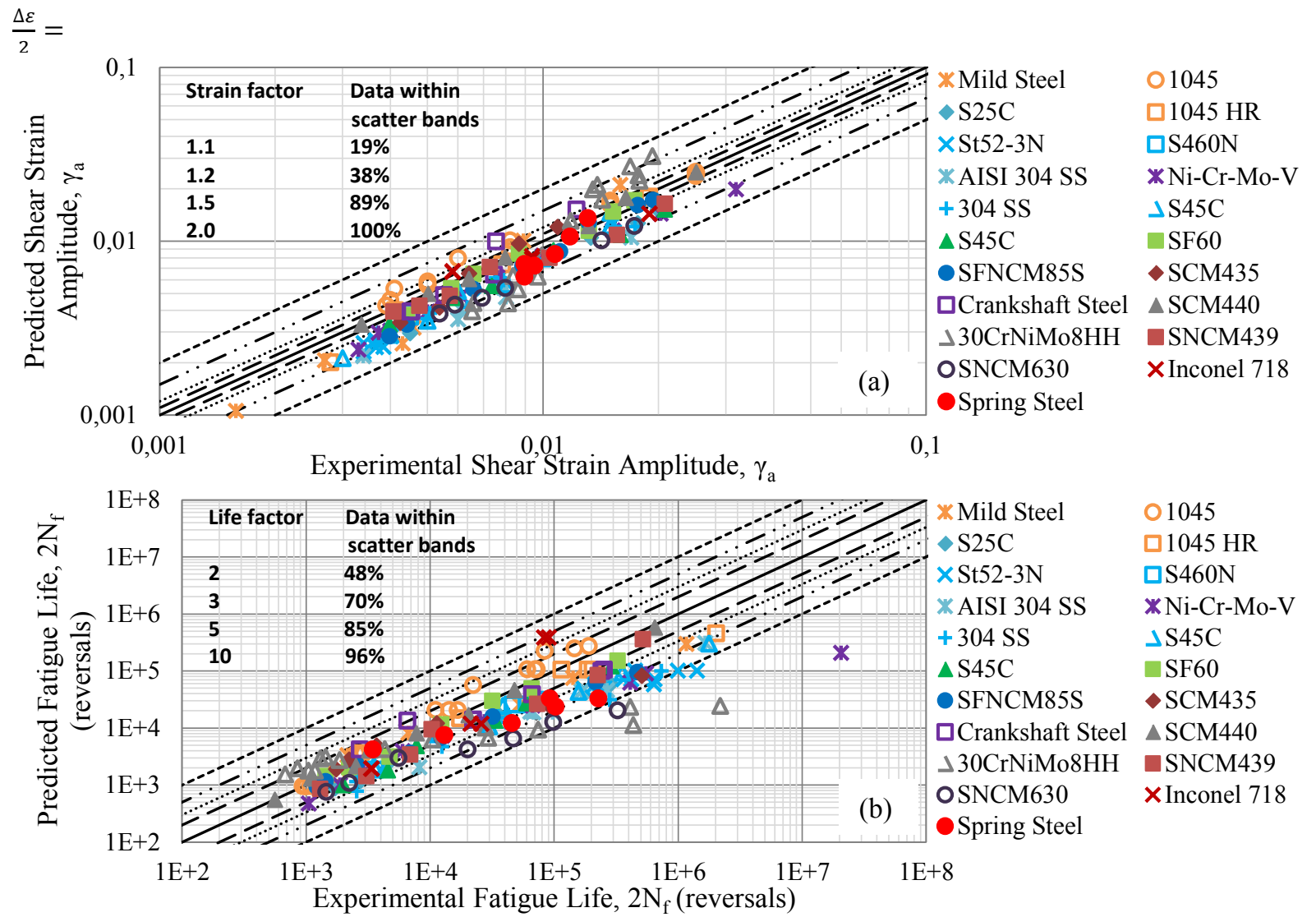

Fig. 1. Results of predictions of (a) shear strain amplitudes and, (b) fatigue lives of torsion fatigue tests on steels and Inconel 718 from shear fatigue properties estimated from experimental uniaxial fatigue properties. Maximum principal strain criterion is used for correlation of spring steel while the rest of the materials are correlated using von Mises effective strain criterion.

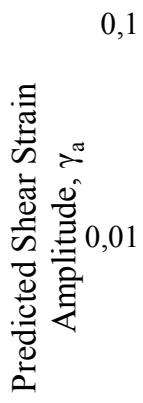

0,001

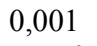

0,001

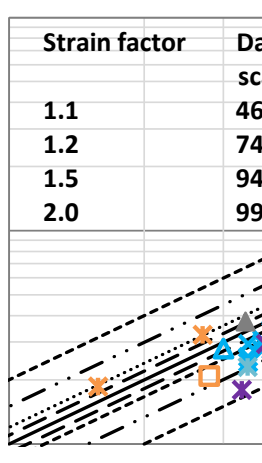

Experimental Shear Strain Amplitude, $\gamma$

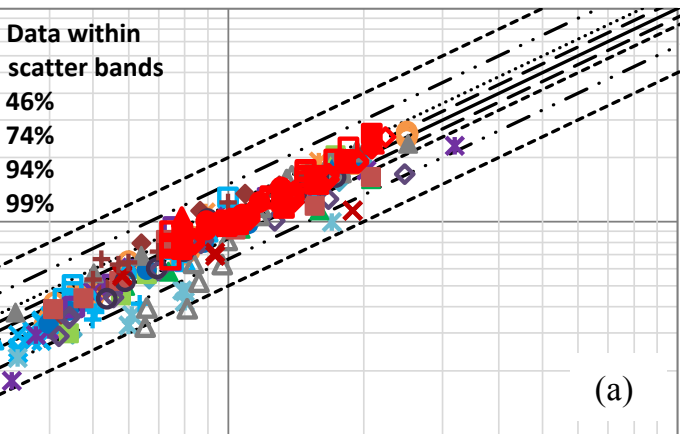

(a)
* Mild Steel $\mathrm{S} 25 \mathrm{C}$
$\times \mathrm{St} 52-3 \mathrm{~N}$

* AISI 304 SS

+304 SS

$\triangle \mathrm{S} 45 \mathrm{C}$

- SFNCM85S

$\square$ Crankshaft Steel

$\triangle \mathrm{SCM} 440$

SNCM439

XInconel 718

Spring Steel

52100 Type C $\checkmark 52100$ Type A

0,1

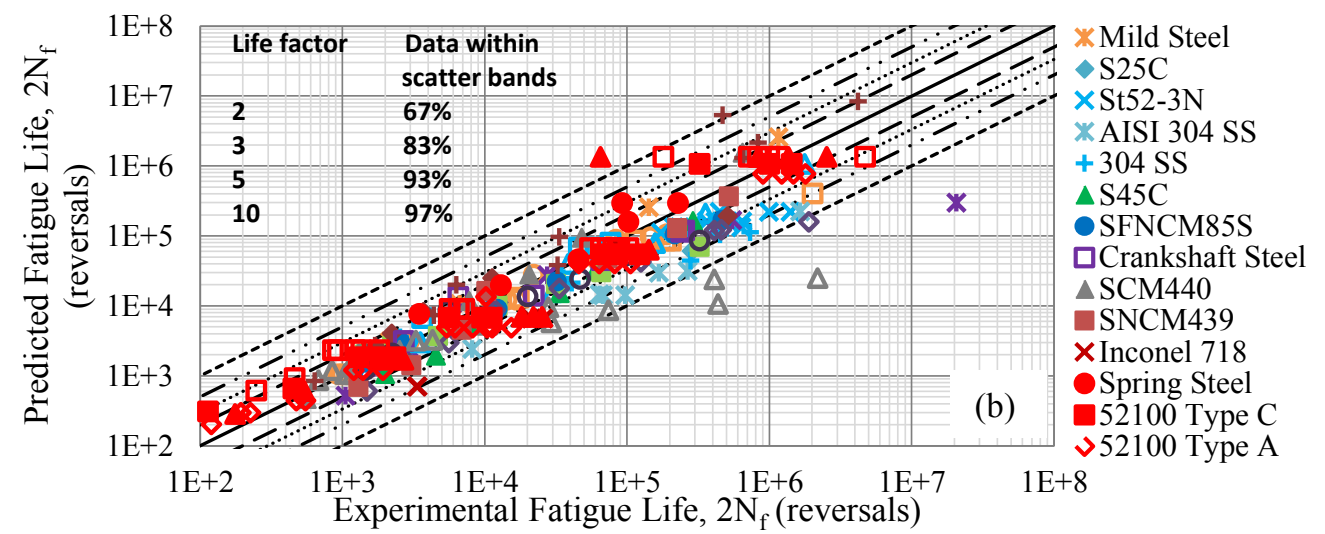

01045

$\square 1045 \mathrm{HR}$

$\square$ S460N

* Ni-Cr-Mo-V

$\triangle \mathrm{S} 45 \mathrm{C}$

SF60

- SCM435

$\checkmark 605 \mathrm{H} 32$ at $600{ }^{\circ} \mathrm{C}$

$+30 \mathrm{CrNiMo} 8 \mathrm{HH}$

OSNCM630

$+605 \mathrm{H} 32$ at $300^{\circ} \mathrm{C}$

$\square 52100$ Type E

$\triangle 52100$ Type B

01045

$\square 1045 \mathrm{HR}$

$\square \mathrm{S} 460 \mathrm{~N}$

* Ni-Cr-Mo-V

$\triangle \mathrm{S} 45 \mathrm{C}$

SF60

SCM435

$\checkmark 605 \mathrm{H} 32$ at $600{ }^{\circ} \mathrm{C}$

$\triangle 30 \mathrm{CrNiMo} 8 \mathrm{HH}$

OSNCM630

$+605 \mathrm{H} 32$ at $300{ }^{\circ} \mathrm{C}$

$\square 52100$ Type E

$\triangle 52100$ Type B 
Fig. 2. Results of predictions of (a) shear strain amplitudes and, (b) fatigue lives of torsion fatigue tests on steels and Inconel 718 from shear fatigue properties calculated from uniaxial fatigue properties estimated from Roessle-Fatemi hardness method. Maximum principal strain criterion is used for correlation of spring steel, $605 \mathrm{H} 32$ at $300^{\circ} \mathrm{C}$, and 52100 steels while the rest of the materials are

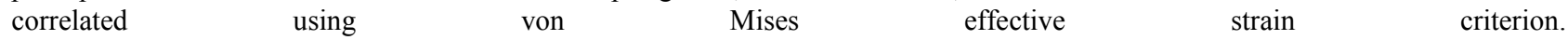
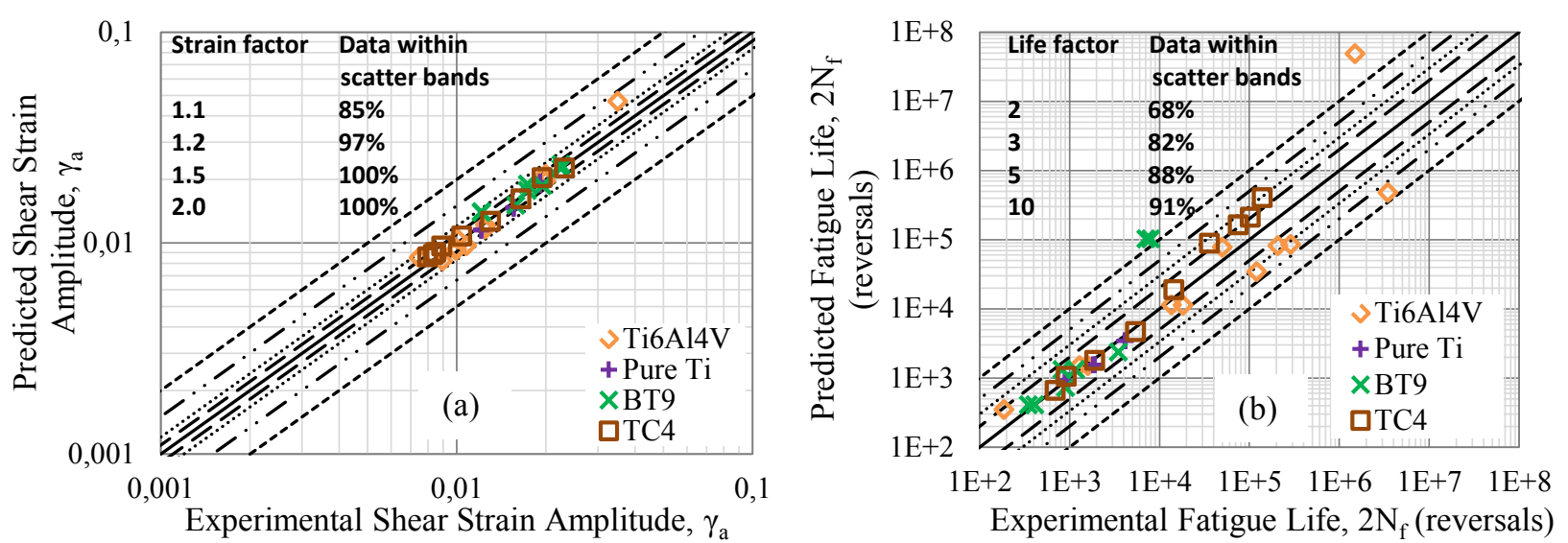

Fig. 3. Results of predictions of (a) shear strain amplitudes and, (b) fatigue lives of torsion fatigue tests on titanium alloys from shear fatigue properties estimated from experimentally obtained uniaxial fatigue properties and based on von Mises effective strain.

The prediction results based on the modified Roessle-Fatemi method for uniaxial and torsion tests are shown in Figures 4 and 5, respectively. It can be observed that using the modified Roessle-Fatemi method results in reasonable predictions of strain amplitude and fatigue life in both uniaxial and torsion fatigue tests. Moreover, a comparison between Figures 3 and 5 shows that the prediction results from the modified Roessle-Fatemi method are as accurate as

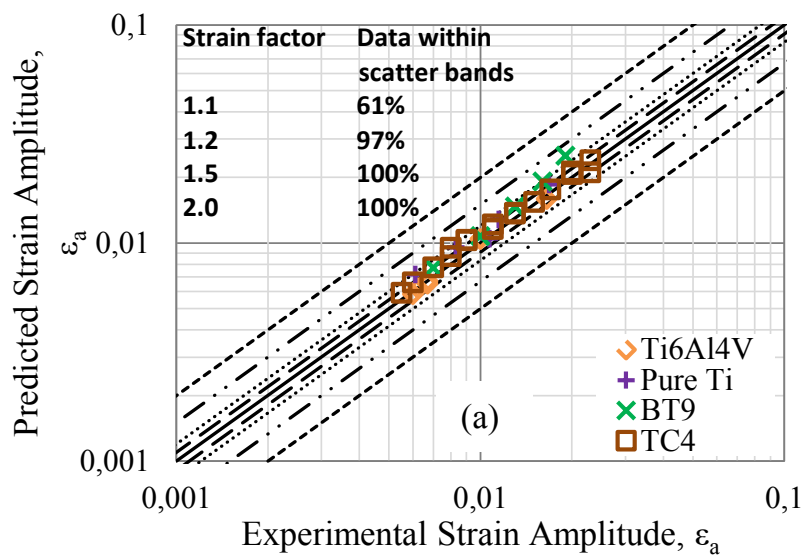

those from experimentally obtained uniaxial fatigue properties.

It should be noted that the relationship shown in Eq. 7 was calculated based on the uniaxial fatigue properties of the 4 titanium alloys used in the data pool of this study. Therefore, due to the limited number of the materials this equation may not result in reasonable predictions for titanium alloys with Brinell hardness of lower than 240 such as titanium alloy grades 1, 2, and 7, or higher than 353 such as Ti-6Al-4V-2Sn alloy.

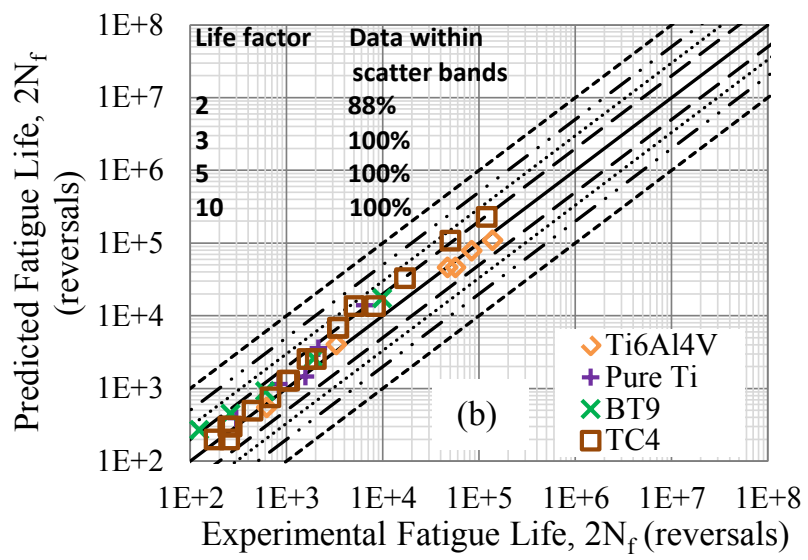

Fig. 4. Results of predictions of (a) uniaxial strain amplitudes and, (b) fatigue lives of uniaxial fatigue tests on titanium alloys estimated from modified Roessle-Fatemi hardness method and based on von Mises effective strain. 

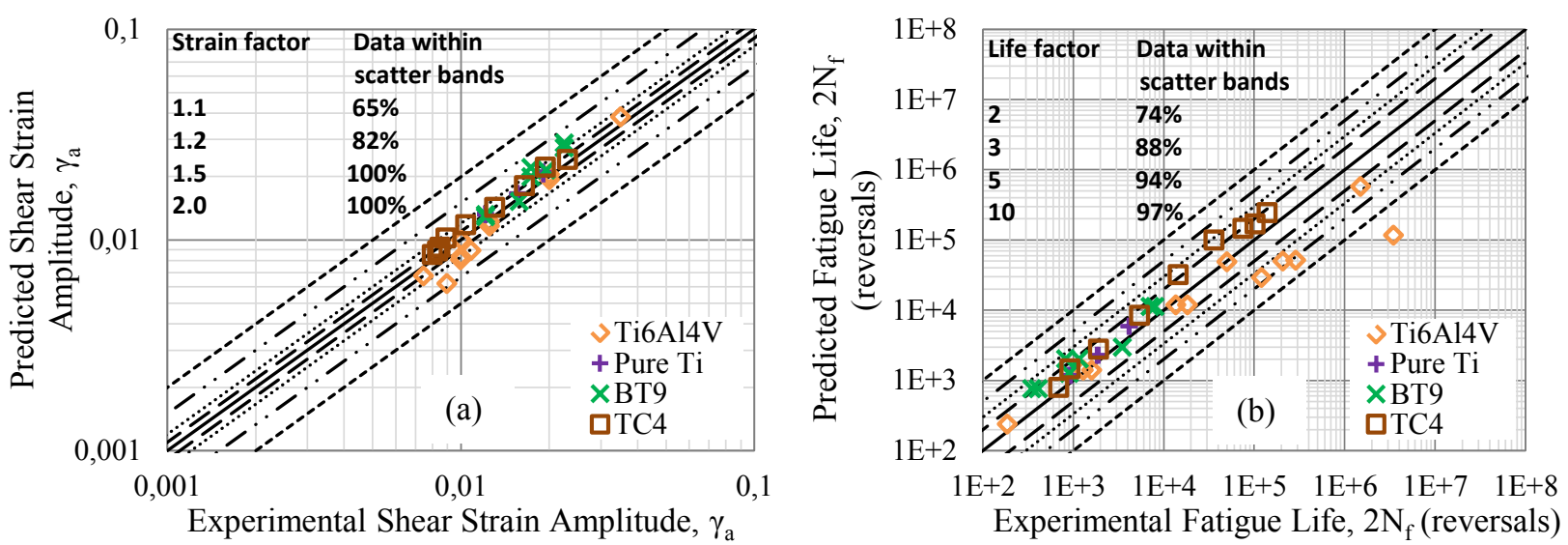

Fig. 5. Results of predictions of (a) shear strain amplitudes and, (b) fatigue lives of torsion fatigue tests on titanium alloys from shear fatigue properties estimated from modified Roessle-Fatemi hardness method and based on von Mises effective strain.

\section{Summary and Conclusions}

Axial monotonic as well as axial and torsion fatigue tests were performed on two types of steel and one titanium alloy. The test data of these tests along with the test data from 23 types of carbon steel, 4 types of titanium alloy, and Inconel 718 were used to evaluate different criteria in estimating shear fatigue properties from experimentally obtained or estimated uniaxial fatigue properties. The steels used in the data pool of this study consisted of both ductile and brittle behaving steels. Steels with ultimate tensile strength of 1100 $\mathrm{MPa}$ or less $(\mathrm{HB} \leq 327)$ were classified as ductile behaving and von Mises effective strain criterion was used to correlate their data. Moreover, steels with ultimate tensile strength of $1696 \mathrm{MPa}$ or more (HB $\geq$ 443) were classified as brittle behaving and maximum principal strain criterion was used to correlate their data. For titanium alloys von Mises effective strain criterion was used for the correlations. The main conclusions drawn from the data analysis conducted are as follows:

1. von Mises and maximum principal strain criteria for ductile and brittle behaving steels, respectively, resulted in strong correlations between the uniaxial fatigue properties and shear fatigue data. Similar results were observed for titanium alloys and Inconel 718 using von Mises effective strain.

2. Using the Brinell hardness and elastic modulus uniaxial fatigue properties of steels and Inconel 718 were estimated by Roessle-Fatemi method. Then, using the suitable correlation criterion shear fatigue properties were calculated from estimated uniaxial fatigue properties. This method resulted in predictions which in some cases were better than the predictions from the experimentally obtained uniaxial fatigue properties.

3. A modified Roessle-Fatemi method in which the equation for calculation of fatigue ductility coefficient was modified based on the uniaxial fatigue properties of titanium alloys was developed. The prediction results based on this method were as reasonable as those from the experimentally obtained uniaxial fatigue properties. The modified equation for calculation of fatigue ductility coefficient was derived for titanium alloys with hardness in the range between 240 and 353.

\section{References}

1. R.I. Stephens, A. Fatemi, R.R. Stephens, H.O. Fuchs, Metal fatigue in engineering (2000)

2. S. Manson, Exp. Mech., 5, 193-226, (1965)

3. J. Ong, Int J Fatigue, 15, 213-219, (1993)

4. U. Muralidharan, S. Manson, J Eng Mater Technol, 110, 55-58, (1988)

5. A. Bäumel, T. Seeger, C. Boller, Amsterdam: Elsevier, (1990)

6. M. Roessle, A. Fatemi, Int J Fatigue, 22, 495-511, (2000)

7. K. Kim, X. Chen, C. Han, H. Lee, Int J Fatigue, 24, 783-793, (2002)

8. M. Meggiolaro, J. Castro, Int J Fatigue, 26, 463476, (2004)

9. A. Fatemi, N. Shamsaei, Int J Fatigue, 33, 948958, (2011)

10. K.-S. Lee, J.-H. Song, Int J Fatigue, 28, 386-400, (2006)

11. A. Fatemi, D.F. Socie, FFEMS, 11, 149-165, (1988)

12. N. Shamsaei, A. Fatemi, Int J Fatigue, 31, 13861396, (2009)

13. G.E. Leese, J. Morrow, Multiaxial Fatigue, ASTM International, (1985)

14. ASTM-E2207-08, Annual Book of ASTM Standards, 03.01, (2012)

15. ASTM-E1012-12, Annual Book of ASTM Standards, 03.01, (2012)

16. N.J. Hurd, P.E. Irving, Multiaxial Fatigue, ASTM International, (1985)

17. S.M. Moghaddam, J.A. Bomidi, F. Sadeghi, N. Weinzapfel, A. Liebel, Tribology International, 77,196-210, (2014)

18. V. Doquet, ICBMFF3, (2013) 
19. A. Fatemi, R.I. Stephens, Multiaxial Fatigue: Analysis and Experiment, 121-137, (1989)

20. P. Lopez-Crespo, B. Moreno, A. Lopez-Moreno, J. Zapatero, Engineering Fracture Mechanics, 136, 115-130, (2015)

21. Y. Jiang, O. Hertel, M. Vormwald, Int J Fatigue, 29, 1490-1502, (2007)

22. D. Socie, J Eng Mater Technol, 109, 293-298, (1987)

23. R.A. Williams, R.J. Placek, O. Klufas, S.L. Adams, D.C. Gonyea, Multiaxial Fatigue, ASTM International, (1985)

24. K. Kim, B. Lee, J. Park, Fatigue and Fracture Mechanics, ASTM International, 31, (2000)
25. K. Kim, J. Park,J. Lee, J Eng Mater Technol, 121, 286-293, (1999)

26. M. Noban, H. Jahed, S. Winkler, A. Ince, Materials Science and Engineering: A, 528, 24842494, (2011)

27. N. Shamsaei, M. Gladskyi, K. Panasovskyi, S. Shukaev, A. Fatemi, Int J Fatigue, 32, 1862-1874, (2010)

28. Z.-R. Wu, X.-T. Hu, Y.-D. Song, Int J Fatigue, 59, 170-175, (2014)

29. J.L. Koch, M.S. Thesis, Mechanical Engineering, University of Illinios at Urbana-Champaign, Champaign, IL, (1985) 